\title{
EVALUATION OF THE SEASONAL NIGHTTIME LST-AIR TEMPERATURE DISCREPANCIES AND THEIR RELATION TO LOCAL CLIMATE ZONES (LCZ) IN STRASBOURG
}

\author{
“ \\ S. Del Pozo ${ }^{1, *}$, T. Landes ${ }^{2}$, F. Nerry ${ }^{3}$, P. Kastendeuch ${ }^{3}$, G. Najjar ${ }^{3}$, N. Philipps ${ }^{3}$, S. Lagüela ${ }^{1}$ \\ ${ }^{1}$ Department of Cartographic and Land Engineering, University of Salamanca, Ávila, Spain - (s.p.aguilera, sulaguela)@ usal.es \\ 2 ICube Laboratory, Photogrammetry and Geomatics Group, National Institute of Applied Sciences (INSA), \\ Strasbourg, France- tania.landes@insa-strasbourg.fr \\ ${ }^{3}$ ICube Laboratory, UMR 7357 CNRS-University of Strasbourg, Illkirch, France - (georges.najjar, kasten, f.nerry)@unistra.fr, \\ nathaliaphilipps@gmail.com
}

Commission III, WG III/8

KEY WORDS: Land Surface Temperature, Air Temperature, Local Climate Zones, Satellite Remote Sensing, Urban Heat Island, MODIS, ASTER

\begin{abstract}
:
More and more uses and applications are being given to local climate zone (LCZ) maps, which describe the structure of the urban and semi-urban areas. Among others, it is worth highlighting its use in studies of urban heat islands (UHI), sustainability and urban energy balance. Even if the classes are well described in the literature, it is difficult to estimate the general precision of these classification maps because the classification is highly dependent of the urban typology of the city under study. However, LCZ maps represent a reference in the field of urban climatology. This research work aims to make use of these maps to explain the strong influence of LCZ classes on land surface temperature (LST) and, consequently, on air temperature (AT). This kind of investigations will help us to explain the outliers observed in previous work between LST and AT at specific locations in the city of Strasbourg for the period 2012-2019. The LST data were obtained from the thermal infrared data of both ASTER (with 90-m spatial resolution and 16-days temporal resolution) and MODIS satellite (with 1-km spatial resolution and daily revisit period). The reference ATs were obtained from different field measurement provided by a huge network of meteorological stations distributed in the city of Strasbourg. The comparison of measured ATs and remote LSTs provide the opportunity to thoroughly evaluate the relationship between these two parameters both during the day and night, for different land covers and for different times of the year. Finally, UHI maps of Strasbourg for every season are presented.
\end{abstract}

\section{INTRODUCTION}

\subsection{Land Surface Temperature and Air temperature}

In the context of characterizing urban heat islands (UHIs), there is still the challenge of quantifying their intensity and characterizing their spatial distribution due to the compromise between the temporality and spatiality of the data. In this context, the climatic parameter that is mainly analysed is the AT. Although it is a parameter measured with a high temporal resolution, it is a discrete measurement obtained from meteorological stations located in specific areas of cities. Based on numerical interpolation models (Cho et al., 2020), it is possible to extrapolate AT for larger areas. However, the mapping of AT is not carried out with guarantees of sufficient precision, especially given the heterogeneity of urban areas. In this sense, remote sensing techniques offer advantages due to their spatial and synoptic coverage, in such a way that remote sensing is becoming widely used to evaluate UHIs, as in (Badaro-Saliba et al., 2021). Even if satellite data provide LST from thermal infrared data (like ASTER and MODIS), we observed a correlation between LST and AT, as mentioned in (Del Pozo et al., 2020).

Not only LST measurements, but also the existence of vegetation, cloudiness and dense urban and peri-urban areas, are important for the quantification of UHIs.
The comparison of measured AT and remote LSTs provide the opportunity to thoroughly evaluate the relationship between these two parameters both during the day and night, for different land covers and for different times of the year.

\subsection{Local Climate Zones}

One way to measure the relationship between urban morphology and UHIs is through the knowledge of the local climatic zones (LCZ) of the study area (Stewart and Oke, 2012; Zhou et al., 2020). The LCZ classification has 17 standard types, summarized in Table 1 (Cai et al., 2018) describing built classes and land cover classes. This kind of classification helps to explain not only the UHI effect between urban and rural areas but also inside a city (Kwok et al., 2019; Ochola et al., 2020) due to the influence that the heterogeneous urban morphology has on the generation of local climate. In addition, the multitemporal land cover change could be studied by analysing the LCZ and LST changes over years (Wang et al., 2019; Quan, 2019). In this way, each LCZ is supposed to have a homogeneous air temperature and surface properties.

\begin{tabular}{ll}
\hline Built series & Land cover series \\
\hline LCZ 1: Compact high-rise & LCZ A: Dense trees \\
LCZ 2: Compact mid-rise & LCZ B: Scattered trees \\
LCZ 3: Compact low-rise & LCZ C: Bush, scrub \\
LCZ 4: Open high-rise & LCZ D: Low plants
\end{tabular}

\footnotetext{
* Corresponding author
} 
LCZ 5: Open mid-rise

LCZ 6: Open low-rise

LCZ 7: Lightweight low-rise

LCZ 8: Large low-rise

LCZ 9: Sparsely built

LCZ 10: Heavy industry

Table 1. Description of Local Climate Zones as defined by (Cai et al., 2018).

After the presentation of the study area and the available LCZ and land cover classification maps, the methodology used to analyse the results is presented.

\section{CASE STUDY AND DATASETS}

\subsection{Study Area}

The study is focused on the Eurometropolitan area of Strasbourg (France), of $340 \mathrm{~km}^{2}$ with a population density of 1.500 inhabitants per $\mathrm{km}^{2}$.

\subsection{LST and Air Temperature Data}

AT data was recorded by 47 meteorological stations. The LST data used for the nighttime LST-AT correlations is the same than in the previous study (Del Pozo et al., 2020) from ASTER and MODIS satellites; specifically, AST-08 and MOD11-L2 products. The spatial resolution of these products is $90 \mathrm{~m}$ and $1 \mathrm{~km}$, respectively.

The correlation LST-AT at night for the period 2012-2019 has already been evaluated, but with a few unexplained outliers. In this paper we suggest evaluating the influence of surface coverage on this correlation, which might be the main reason leading to outliers.

\subsection{LCZ Classification}

A LCZ classification map (Figure 1) has already been created for the Eurometropolitan area of Strasbourg (Landes et al., 2020). Since the location of each meteorological station is known, the urban characteristics of the area to which each station belongs can be extracted. Based on our study, it is intended that: 1) the LCZ map explains the largest discrepancies obtained between the LST-AT correlations between 2012-2019, and that 2) it serves as a basis to analyse its accuracy in terms of the spatial coverage per class and the influence that neighbouring surface covers may have on each LCZ class.

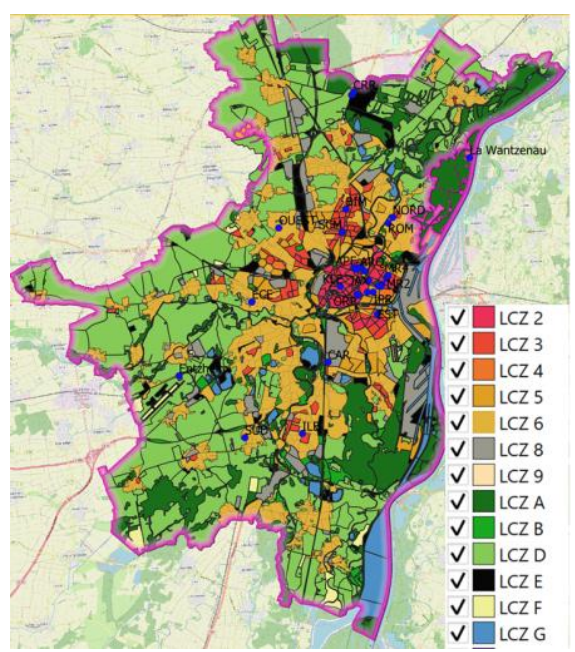

Figure 1. Local Climate Zone map and of the Eurometropolitan area of Strasbourg.

\subsection{Land Use Classification}

To check if the surface coverage might explain outliers of the correlation mentioned above, a land use map provided by the Open Data Strasbourg website of Eurométropole Strasbourg has also been considered. Presented in Figure 2, it distinguishes 18 classes and has been produced based on satellite data (in checking process).

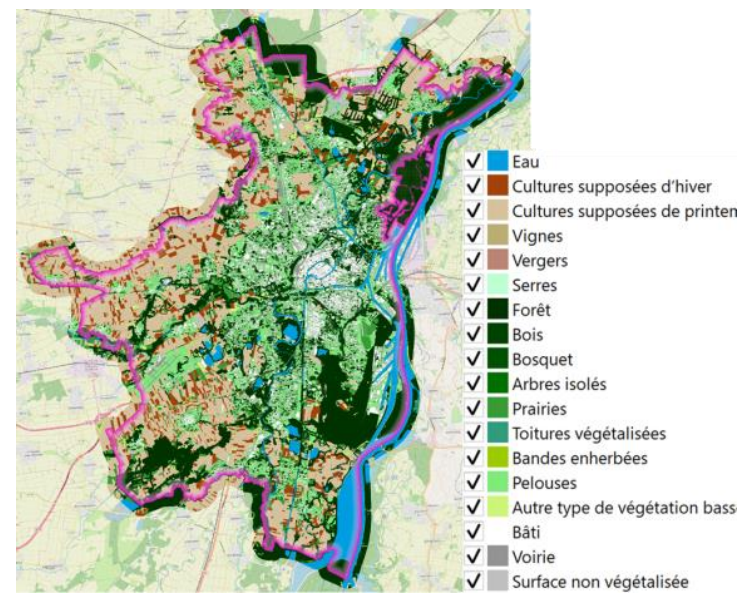

Figure 2. Land uses of the Eurometropolitan area of Strasbourg (source: openDataStrasbourg).

\section{METHODOLOGY}

Apart from the AT data extracted by the 47 meteorological stations, LST data from satellite observation was also analyzed. Specifically, AST08 and MOD11 L02 satellite products, from ASTER and MODIS respectively. All the available nighttime LST images from both satellite sensors onboard Terra platform were downloaded from 2012 to 2019. On the one hand, they were processed to obtain the average LST by season of the year and, on the other, the image closest to the considered "typical day", representative of each season of the year, was used to compare. For the latter, the typical date was chosen for a latitude $50 \mathrm{~N}$, being Strasbourg at latitude $48 \mathrm{~N}$, as established by (Capderou, 1988).

\subsection{Analysis of LCZ Effect on Temperatures}

The nighttime LST-AT correlation has been analyzed per LCZ for the 47 meteorological station locations reaching a coefficient of determination $\mathrm{R}^{2}$ of 0.9381 and 0.8221 from AST-08 and MOD11-L2 products respectively (Del Pozo et al., 2020). To better understand the relationship between LST-AT per LCZ and in order to explain the outliers found in the precursor study, following investigations have been performed: 1) analysis of the variations of LST inside a LCZ; 2) analysis of the variability of LST regarding LCZ and time; and 3) analysis of the mean LST by LCZ and season.

3.1.1 LST-AT per LCZ: 8 types of LCZs describe the urban morphology of the 47 locations of the meteorological stations of the precursory study. Analysing the LST-AT correlation for these 8 classes, better correlations were, in general terms, obtained than by analysing the data as a whole (Table 2).

3.1.2 LST Variations per LCZ and Time Period: For this study, and since AT is not analyzed here, apart from the location of the 47 meteorological stations, a grid of 397 additional locations has been generated with a spacing of $1 \mathrm{~km} \mathrm{x}$ 
$1 \mathrm{~km}$ for the entire study area (Figure 5) in order to more deeply analyze LST variations per LCZ.

The temperature variation $(\triangle \mathrm{LST})$ per LCZ was calculated for the seasons within the 8-year period between 2012 and 2019 taking into account (i) all available cloudless data for each season and year, and (ii) only the typical day of each season and year to validate the use of typical days for mapping the UHI effect. The typical days that represent each season for a latitude $50 \mathrm{~N}$ (Capderou, 1988) are:

- Winter: January 17

- Spring: April 15

- Summer: July 17

- Autumn: October 16

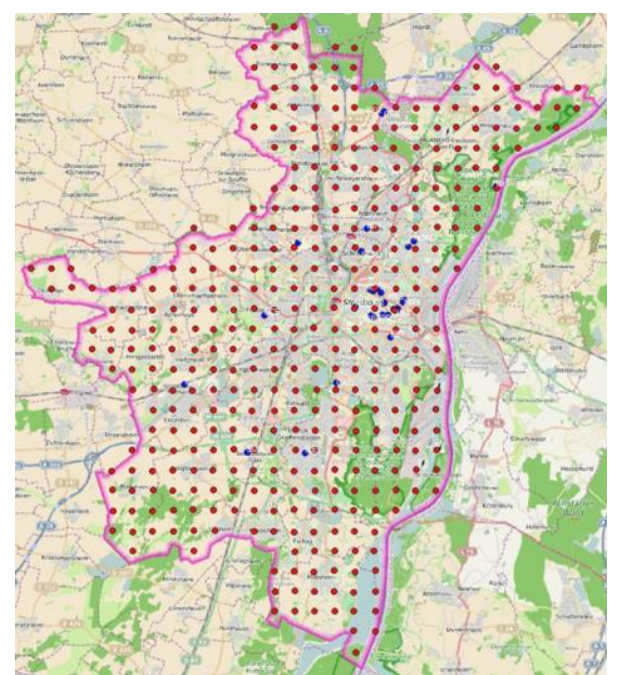

Figure 5. Grid of 444 points for which LST and LCZ data was analysed.

Prior to the study by LCZ, the LST variation obtained per point of the grid was evaluated. This variation was calculated between (1) the LST average of all the available data per season and (2) the average between the typical days per season In this regard, a maximum variation of $4.36 \mathrm{~K}$ and a mean variation of $3.12 \mathrm{~K}$ (std of $0.42 \mathrm{~K}$ ) was obtained, occurring the least variation in summer. From this analysis the possibility of using only the typical days to make studies of LSTs by season or obtain the UHI map by season is proved.

\section{RESULTS AND DISCUSSION}

\subsection{LST-AT per LCZ}

As Table 2 shows, better LST-AT correlation was obtained by analysing all available AST-08 images than MOD11-L2 images. Also, better results were obtained when we evaluate such correlation per LCZ. This is due to the better spatial resolution offered by ASTER (90m) compared to MODIS (1 km) for the thermal data. A MOD11-L2 pixel covers a larger area, so that each pixel is more likely to contain a mixture of LCZ classes (Figure 4).

\begin{tabular}{ccc}
\hline LCZ & R $^{2}$ ASTER DATA & $\mathbf{R}^{2}$ MODIS DATA \\
\hline LCZ-2 & 0.9745 & 0.9060 \\
LCZ-3 & 0.9621 & 0.5825 \\
LCZ-5 & 0.9675 & 0.7865 \\
LCZ-6 & 0.8994 & 0.8298 \\
LCZ-8 & 0.9719 & No data \\
LCZ-A & 0.9423 & 0.7714 \\
\hline
\end{tabular}

\begin{tabular}{ccc}
\hline LCZ-B & 0.7484 & 0.9377 \\
LCZ-D & 0.9537 & 0.8810 \\
\hline
\end{tabular}

Table 2. Correlation between LST and AT per LCZ describing the urban morphology of the 47 locations of the meteorological

$$
\text { stations. }
$$

For ASTER data, the LST-AT correlation per LCZ improves in all cases except for LCZ-6 ( $\mathrm{R}^{2}$ of 0.8994$)$ and LCZ-B $\left(\mathrm{R}^{2}\right.$ of $0.7484)$. LCZ-6 is defined by open low-rise and LCZ-B by scattered trees. Therefore, the results mean that the effect of surrounding classes on an isolated class is not sufficiently considered. Figure 3 shows the positions of two meteorological stations with high absolute error, La Wantzenau (LCZ 6, Figure 3-left) and RER (LCZ B, Figure 3-right) which are small LCZ surrounded by other greater LCZs: LCZ-A, LCZ-E and LCZ-G in La Wantzenau, and LCZ-E and LCZ-D in RER.
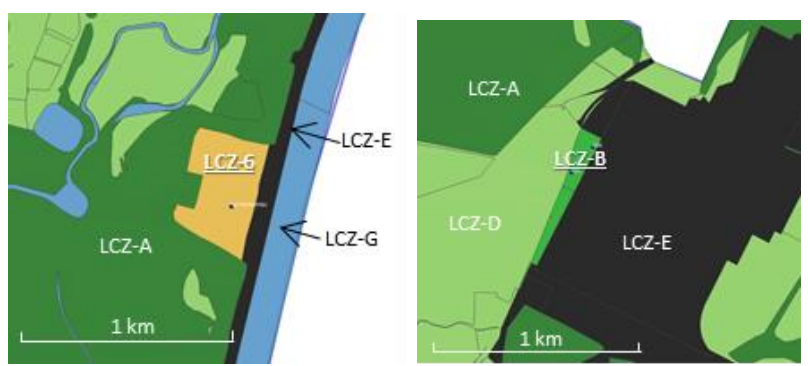

Figure 3. On the left: Position of LCZ-6 surrounded by LCZ-A, LCZ-E and LCZ-G. On the right: Position of LCZ-B surrounded by LCZ-E and LCZ-D.

Regarding MODIS data, the results do not improve for LCZ-3, LCZ-5 and LCZ-A. In this case, the reason is that MODIS pixels have a spatial resolution of $1 \mathrm{~km}$, covering more than one LCZ for many cases of study. Thus, the LST obtained from MOD11 L02 product includes the LST from more LCZs than the predominant (Figure 4).

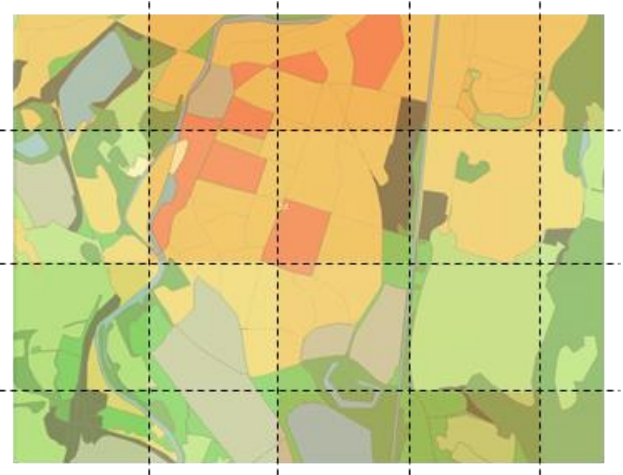

Figure 4. Example showing how MOD11-L2 pixels cover more than one LCZ.

By discarding the thermal data from La Wantzenau (LCZ-6 and main outlier derived from the previous study), highly influenced by the LCZs around it, the LST-AT correlation for ASTER and MODIS improves both (i) by analyzing all the data as a whole ( $\mathrm{R}^{2}$ of 0.9521 and 0.8347 for each sensor respectively), and (ii) by analyzing them by LCZ (LCZ-6), obtaining a $\mathrm{R}^{2}$ of 0.9568 and 0.8548 respectively.

\subsection{LST Variations per LCZ and Time Period}

Regarding the study by grouping the grid locations by LCZ classes and using nighttime MODIS data from typical days 
(Figure 6), it was obtained a mean variation of $8.59 \mathrm{~K}$ per LCZ in winters, $9.71 \mathrm{~K}$ in springs, $5.12 \mathrm{~K}$ in summers and $10.17 \mathrm{~K}$ in autumns, with a mean standard deviation of 2.93, 3.07, 1.62 and 3.52 , respectively, for the 2012-2019 period.

Homogeneity of temperature variation by season is observed for all the LCZ except for the LCZ-F (bare soil or sand) for autumn. Which may be due to the fact that there is only 1 of the 444 points of the grid with this urban typology (as occurs for LCZ 4 and 9). In addition, it is striking that, in this case, there seems to be more homogeneity between the summer temperatures of all the years $(\triangle \mathrm{LST}$ of $5.12 \mathrm{~K})$ than in the case of the rest of the seasons.

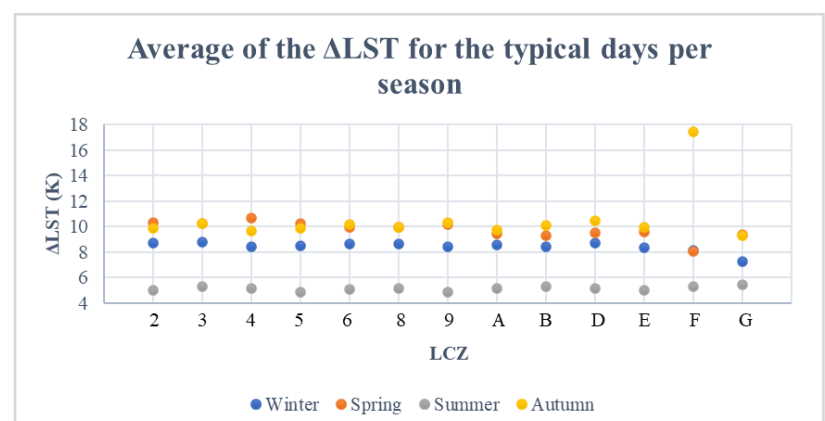

Figure 6. Mean LST per LCZ and season from all MODIS data available.

On the other hand, when analyzing all cloudless nighttime images available from MODIS for the 2012-2019 period (Figure 7), the mean variation of LST are much wider, even doubling the results from the study limited to typical days. A mean variation of LSTs per LCZ were $16.36 \mathrm{~K}$ in winter, $16.34 \mathrm{~K}$ in spring, $15.74 \mathrm{~K}$ in summer, and $14.33 \mathrm{~K}$ in autumn, with a mean standard deviation of $15.67,4.43,4.27$ and 3.16 respectively. The increase in the LST variation respect to Figure 6 can be explained by the range of dates evaluated. In this case, all the days belonging to each season (around 92 days) compared to one specific date per season that is analyzed in Figure 6.

Here, it is also observed that the LCZ-F has a greater discrepancy with respect to the rest of urban morphologies.

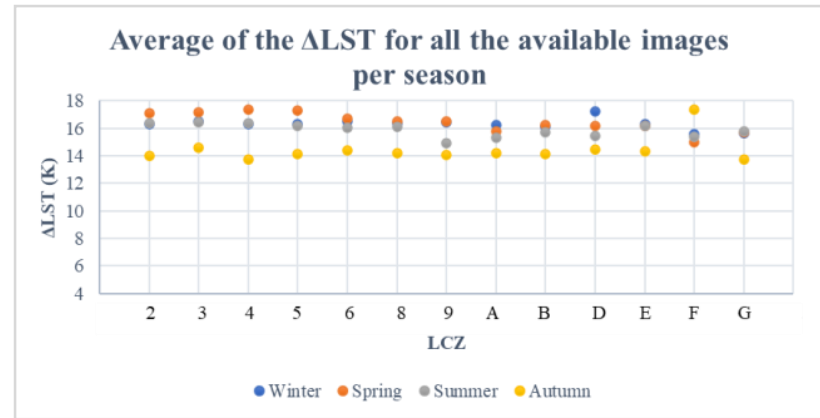

Figure 7. Mean LST per LCZ and season from all MODIS data available.

Table 2 and 3 show the values of the standard deviations by LCZ obtained when analyzing the variation of LST by LCZ and season when considering 1) the typical days for each season respect of considering 2) all the data available by season.

\begin{tabular}{|c|c|c|c|c|}
\hline \multirow{2}{*}{$\mathbf{L C Z}$} & \multicolumn{4}{|c|}{ Standard Deviation (K) } \\
\hline & Winter & Spring & Summer & Autumn \\
\hline Z-2 & 2.92 & 3.33 & 1.58 & 3.52 \\
\hline LCZ-3 & 2.97 & 3.22 & 1.68 & 3.57 \\
\hline
\end{tabular}

\begin{tabular}{lllll}
\hline LCZ-4 & 2.84 & 3.42 & 1.62 & 3.48 \\
LCZ-5 & 2.89 & 3.25 & 1.55 & 3.49 \\
LCZ-6 & 2.94 & 3.12 & 1.62 & 3.54 \\
LCZ-8 & 2.99 & 3.10 & 1.63 & 3.45 \\
LCZ-9 & 2.88 & 3.12 & 1.54 & 3.52 \\
LCZ-A & 2.91 & 2.97 & 1.62 & 3.34 \\
LCZ-B & 2.87 & 2.97 & 1.66 & 3.50 \\
LCZ-D & 3.00 & 3.00 & 1.64 & 3.58 \\
LCZ-E & 2.87 & 3.05 & 1.59 & 3.45 \\
LCZ-F & 2.72 & 2.62 & 1.66 & 5.20 \\
LCZ-G & 2.51 & 3.01 & 1.67 & 3.28 \\
\hline
\end{tabular}

Table 2. Standard deviation of the mean LST variations per LCZ and season from 2012 to 2019 using MODIS data when analysing typical days per season.

\begin{tabular}{|c|c|c|c|c|}
\hline \multirow{2}{*}{$\mathbf{L C Z}$} & \multicolumn{4}{|c|}{ Standard Deviation $(\mathrm{K})$} \\
\hline & Winter & Spring & Summer & Autumn \\
\hline LCZ-2 & 14.86 & 4.49 & 3.27 & 4.34 \\
\hline LCZ-3 & 14.79 & 4.42 & 3.29 & 4.42 \\
\hline LCZ-4 & 15.52 & 4.51 & 3.31 & 4.33 \\
\hline LCZ-5 & 14.34 & 4.45 & 3.23 & 4.36 \\
\hline LCZ-6 & 15.11 & 4.33 & 3.20 & 4.35 \\
\hline LCZ-8 & 14.99 & 4.29 & 3.21 & 4.31 \\
\hline LCZ-9 & 15.37 & 4.30 & 3.05 & 4.18 \\
\hline LCZ-A & 15.67 & 4.10 & 3.07 & 4.25 \\
\hline LCZ-B & 14.25 & 4.23 & 3.13 & 4.31 \\
\hline LCZ-D & 16.68 & 4.23 & 3.12 & 4.30 \\
\hline LCZ-E & 14.64 & 4.25 & 3.20 & 4.30 \\
\hline LCZ-F & 15.28 & 3.98 & 3.10 & 5.03 \\
\hline LCZ-G & 14.45 & 4.13 & 3.11 & 6.86 \\
\hline
\end{tabular}

Table 3. Standard deviation of the mean LST variations per LCZ and season from 2012 to 2019 using MODIS data when analysing all cloudless images available.

It should be noted the high standard deviation obtained for all LCZ in the case of winter (Table 3). Perhaps this could be due to the fact that images with snow cover over the city of Strasbourg may have been analysed. It is proposed to do a more in-depth study to clarify this fact. In addition, a more in-depth analysis should be done to evaluate the discrepancies between the variability of LST by LCZ when the typical day is taken as the representative date of each season of the year with respect to taking the average of the LST images of all the days belonging to each station

Finally, the analysis performed with ASTER data did not provide reliable results, since there were few images available on dates close to typical days. Considering all data available in the $2012-2019$ period (only 15 images), a mean LST variation of $8.59 \mathrm{~K}$ per LCZ was obtained in winter, $9.71 \mathrm{~K}$ in spring, $5.12 \mathrm{~K}$ in summer, and $10.17 \mathrm{~K}$ in autumn, with a standard deviation of $2.93,3.07,1.62$ and 3.52 , respectively.

\subsection{Mean LST by LCZ and Season}

Considering the MODIS data, it is deduced that the average LST per season and for the period 2012-2019 was:

- $\quad$ Winter LST (all data): 275.11K (std 1.06)

- $\quad$ Winter LST (typical days): 271.73K (std 0.79)

- $\quad$ Spring LST (all data): 283.06K (std 1.32)

- $\quad$ Spring LST (typical days): 279.72K (std 1.29) 
- $\quad$ Summer LST (all data): 291.29K (std 1.42)

- $\quad$ Summer LST (typical days): 293.9K (std 1.64)

- $\quad$ Autumn LST (all data): 279.32K (std 1.15)

- $\quad$ Autumn LST (typical days): 282.49K (std 1.25)

This study follows that considering all the data, seasons go from colder to hotter as follows: winter-autumn-spring-summer; not resulting in the same way when analyzing LST variations by typical day per season: winter-spring-autumn-summer.

In addition, from this analysis it is verified that for all the seasons of the year, the distribution of LCZ according to its LST is the same as Figure 8 and 9 show.

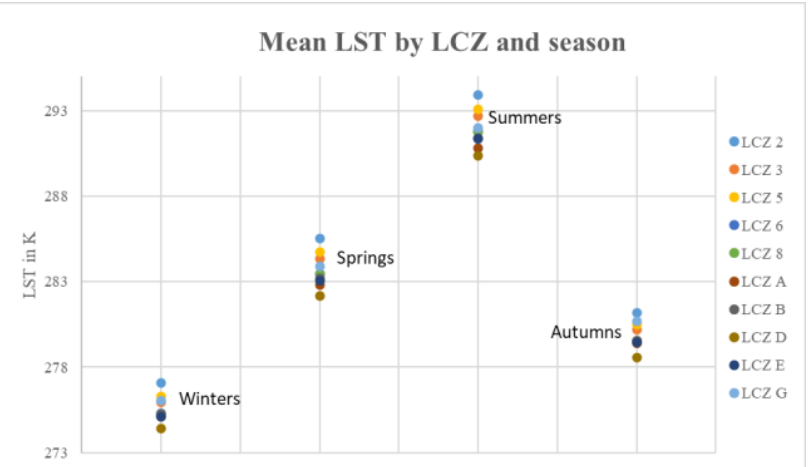

Figure 8. Mean LST per LCZ and season from all MODIS data available.

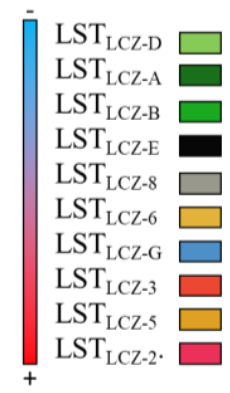

Figure 9. Distribution of LCZs of the study area from lowest to highest LST.

Given this thermal behaviour between built and land cover surfaces. a great similarity is observed between the LCZ map (Figure 1) and that of the UHI effect (Figure 10-13) without being able to derive the UHI intensity or its seasonal variation with the former.

Finally, the comparison of the LST variations between seasons by LCZ has been carried out, obtaining the results of Table 4 . Whether all the data are analyzed or only the typical days per season, a greater homogeneity of temperatures (lower $\triangle \mathrm{LST}$ mean) is obtained for the LCZ-A, LCZ-D and LCZ-G (dense trees, bush-scrub and water) than for the rest LCZ. This means that these natural coverages can serve as temperature regulators and attenuators of the UHI effect. However, evaluating the variation of LST between seasons, we observe that there are discrepancies if we analyze all the data or only the typical days of each season. In the first case, greater variations are observed between summer and autumn for all LCZs and in the second, greater changes are observed between spring and summer, and between autumn and winter with respect to evaluating all the data.

Table 4. Mean LST variations between seasons per LCZ and the standard deviation. $\mathrm{NR}=$ non representative value.

\begin{tabular}{|c|c|c|c|c|c|c|c|c|}
\hline \multirow{3}{*}{ LCZ } & \multicolumn{8}{|c|}{$\triangle$ LST MEAN } \\
\hline & \multicolumn{4}{|c|}{ MODIS ALL DATES } & \multicolumn{4}{|c|}{ MODIS TYPICAL DAYS } \\
\hline & \multicolumn{2}{|c|}{ W-SP SP-SU } & SU-A & \multirow{2}{*}{ A-W } & \multicolumn{2}{|c|}{ W-SP SP-SU } & \multirow{2}{*}{$\begin{array}{c}\text { SU-A } \\
-11,78\end{array}$} & \multirow{2}{*}{$\begin{array}{c}\text { A-W } \\
-11,41\end{array}$} \\
\hline 2 & 8,20 & 8,29 & $-12,21$ & & 8,60 & 14,59 & & \\
\hline 3 & 8,39 & 8,35 & $-12,53$ & $-4,22$ & 8,70 & 14,35 & $-11,67$ & $-11,35$ \\
\hline 4 & NR & NR & NR & NR & NR & NR & NR & NR \\
\hline 5 & 8,44 & 8,38 & $-12,62$ & $-4,20$ & 9,01 & 14,79 & $-12,21$ & $-11,58$ \\
\hline 6 & 8,16 & 8,33 & $-12,30$ & $-4,20$ & 8,28 & 14,41 & $-11,77$ & $-10,92$ \\
\hline 8 & 8,21 & 8,31 & $-12,25$ & $-4,28$ & 8,42 & 14,42 & $-11,78$ & $-11,06$ \\
\hline 9 & NR & NR & NR & NR & NR & NR & NR & NR \\
\hline A & 7,73 & 8,02 & $-11,45$ & $-4,30$ & 7,76 & 13,73 & $-10,69$ & $-10,80$ \\
\hline B & 7,96 & 8,19 & $-11,83$ & $-4,31$ & 8,05 & 14,18 & $-11,39$ & $-10,85$ \\
\hline D & 7,75 & 8,22 & $-11,83$ & $-4,13$ & 7,59 & 13,98 & $-11,26$ & $-10,31$ \\
\hline $\mathrm{E}$ & 8,00 & 8,29 & $-11,92$ & $-4,37$ & 8,17 & 14,22 & $-11,29$ & $-11,10$ \\
\hline $\mathrm{F}$ & NR & NR & NR & NR & NR & NR & NR & NR \\
\hline \multirow[t]{2}{*}{ G } &, 85 & 8,11 & $-11,36$ & $-4,60$ & 7,80 & 13,96 & $-10,68$ & $-11,08$ \\
\hline & \multicolumn{8}{|c|}{ STDV } \\
\hline \multirow[t]{2}{*}{ LCZ } & \multicolumn{4}{|c|}{ MODIS ALL DATES } & \multicolumn{4}{|c|}{ MODIS TYPICAL DAYS } \\
\hline & W-SP & SP-SL & SU-A & A-W & W-SP & SP-SU & SU-A & A-W \\
\hline 2 & 0,44 & 0,21 & 0,94 & 0,35 & 0,88 & 0,62 & 1,20 & 0,41 \\
\hline 3 & 0,23 & 0,13 & 0,32 & 0,12 & 0,55 & 0,36 & 0,55 & 0,43 \\
\hline 4 & NR & NR & NR & NR & NR & NR & NR & NR \\
\hline 5 & 0,31 & 0,16 & 0,54 & 0,18 & 0,32 & 0,46 & 0,70 & 0,16 \\
\hline 6 & 0,38 & 0,16 & 0,53 & 0,17 & 0,62 & 0,43 & 0,63 & 0,49 \\
\hline 8 & 0,34 & 0,15 & 0,50 & 0,18 & 0,64 & 0,44 & 0,64 & 0,56 \\
\hline 9 & NR & NR & NR & NR & NR & NR & NR & NR \\
\hline A & 0,38 & 0,18 & 0,62 & 0,22 & 0,59 & 0,49 & 0,75 & 0,48 \\
\hline B & 0,38 & 0,13 & 0,60 & 0,24 & 0,77 & 0,46 & 0,81 & 0,61 \\
\hline $\mathrm{D}$ & 0,28 & 0,16 & 0,38 & 0,15 & 0,46 & 0,35 & 0,50 & 0,46 \\
\hline $\mathrm{E}$ & 0,32 & 0,15 & 0,55 & 0,25 & 0,51 & 0,39 & 0,71 & 0,41 \\
\hline F & NR & NR & NR & NR & NR & NR & NR & NR \\
\hline G & 0,50 & 0,20 & 1,00 & 0,35 & 0,94 & 0,52 & 1,27 & 0,48 \\
\hline
\end{tabular}

\subsection{Urban Heat Island Mapping for Strasbourg}

Once the nighttime LST-AT model is validated, we are able to provide a UHI map of Strasbourg for the 4 seasons (Figures 1013) based on the representation of LSTs. For this, the mean LST value for each season of the year and pixel is calculated based on the MODIS and ASTER LST data between the years 2012 to 2019.

Although Figure 12c is not complete due to the unavailability of ASTER data, it follows that the morphology of the UHI map of Strasbourg follows a radial distribution with greater intensity in the center of the city, decreasing towards the outskirts. It is observed that the maximum nighttime intensity occurs in summer and in the downtown, reaching $293 \mathrm{~K}$ on average, being the minimum nighttime LST $270 \mathrm{~K}$ in winter and on the outskirts. These maps have been drawn up with the same lookup table for all seasons of the year, therefore slight variations are observed within each season of the year. However, its radial morphology and spatial distribution are verified. Specifically, a temperature variation of up to $6 \mathrm{~K}$ between the downtown and outskirts of Strasburg was observed. In this way, the existence of a microclimatic thermal behavior in the city has been proven.

It should be noted that the natural course of the River Ill as well as the different masses of water greatly influence the morphology of this maps. It is observed how, at night, the 


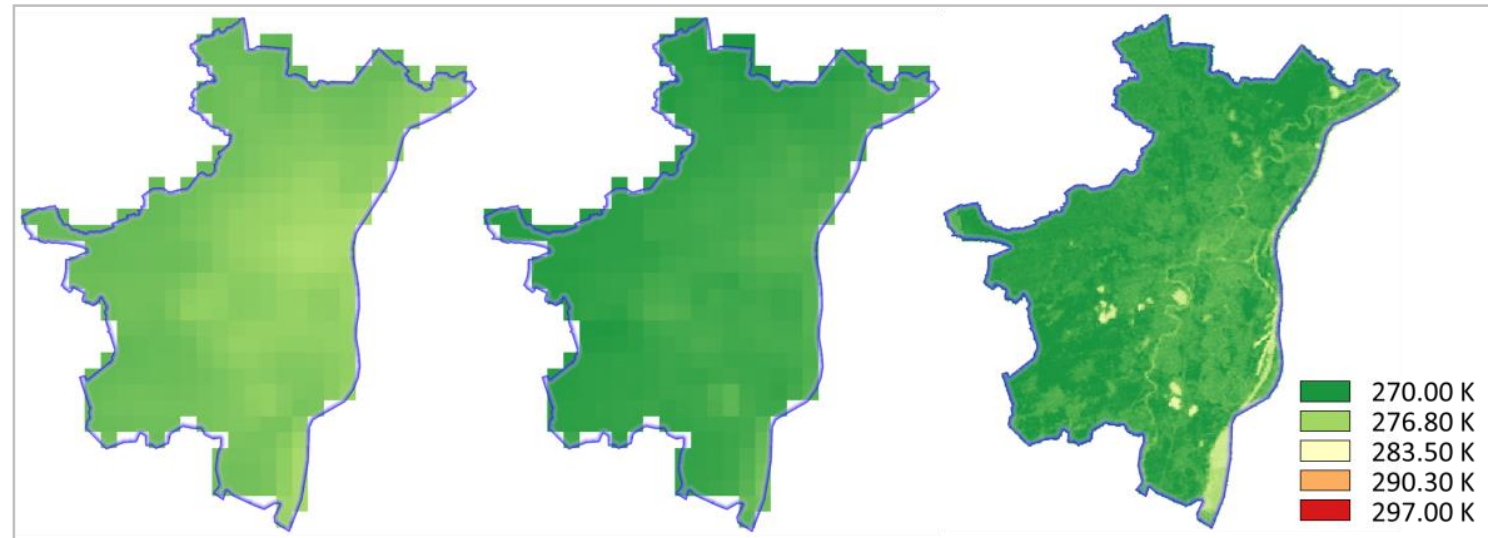

Figure 10. Winter UHI map of Strasbourg at night when analysing all data from MODIS (left), typical days from MODIS (center), and the available data from ASTER (right)
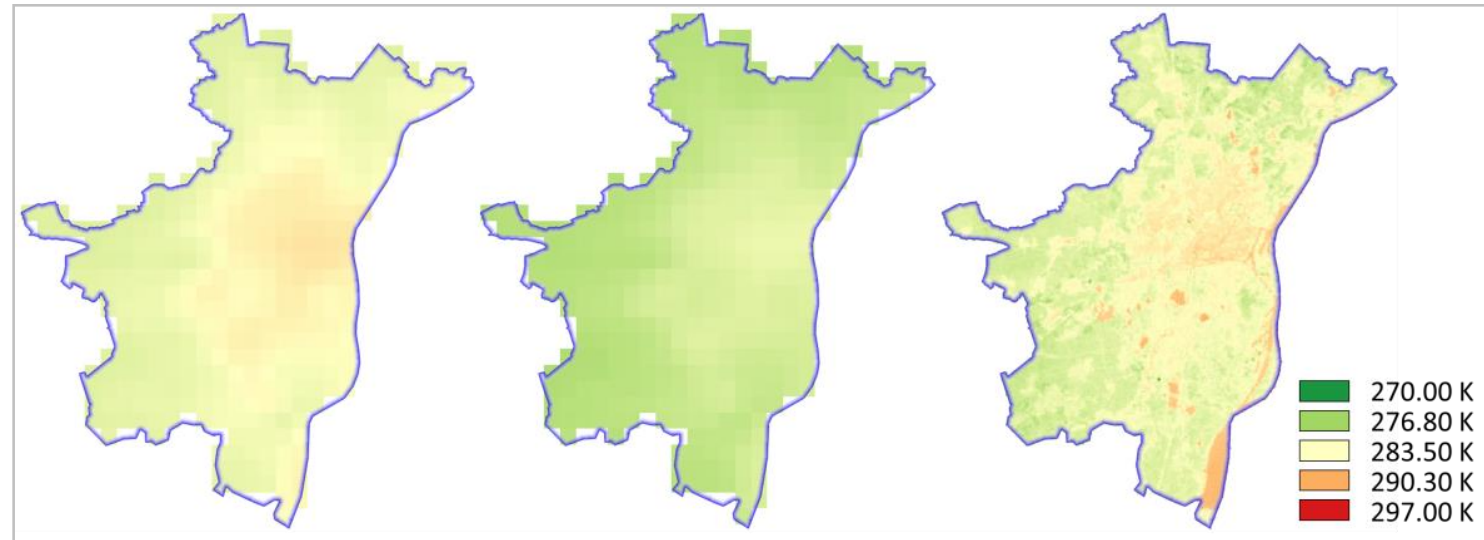

Figure 11. Spring UHI map of Strasbourg at night when analysing all data from MODIS (left), typical days from MODIS (center), and the available data from ASTER (right)

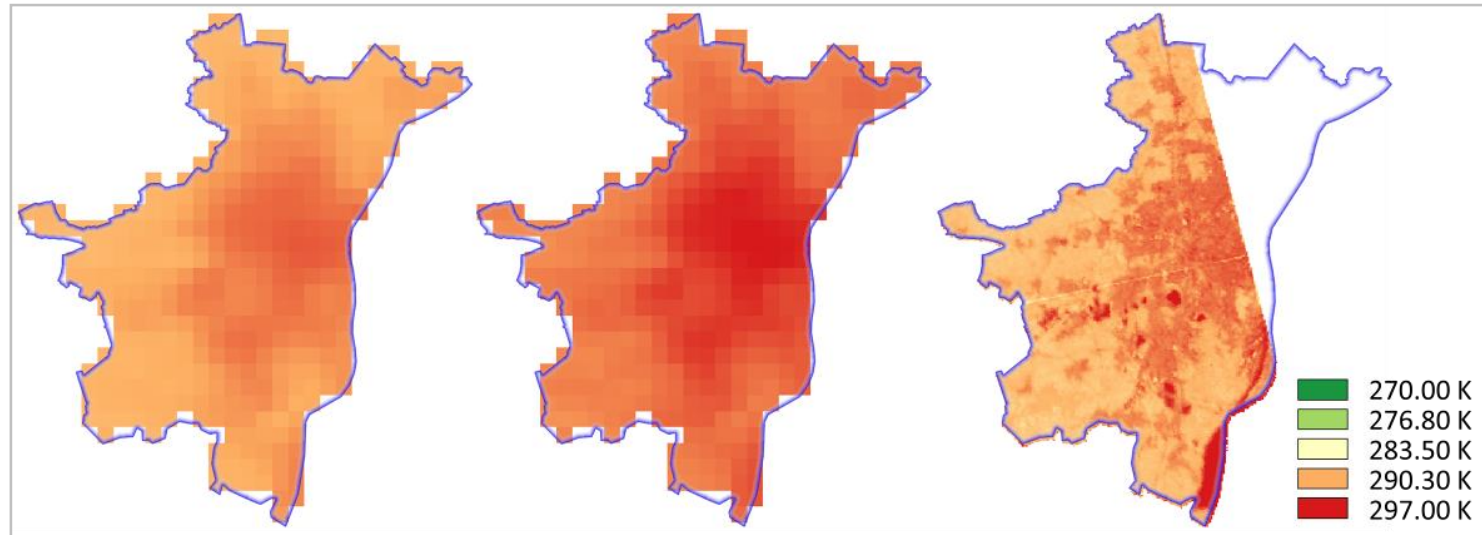

Figure 12. Summer UHI map of Strasbourg at night when analysing all data from MODIS (left), typical days from MODIS (center), and the available data from ASTER (right)

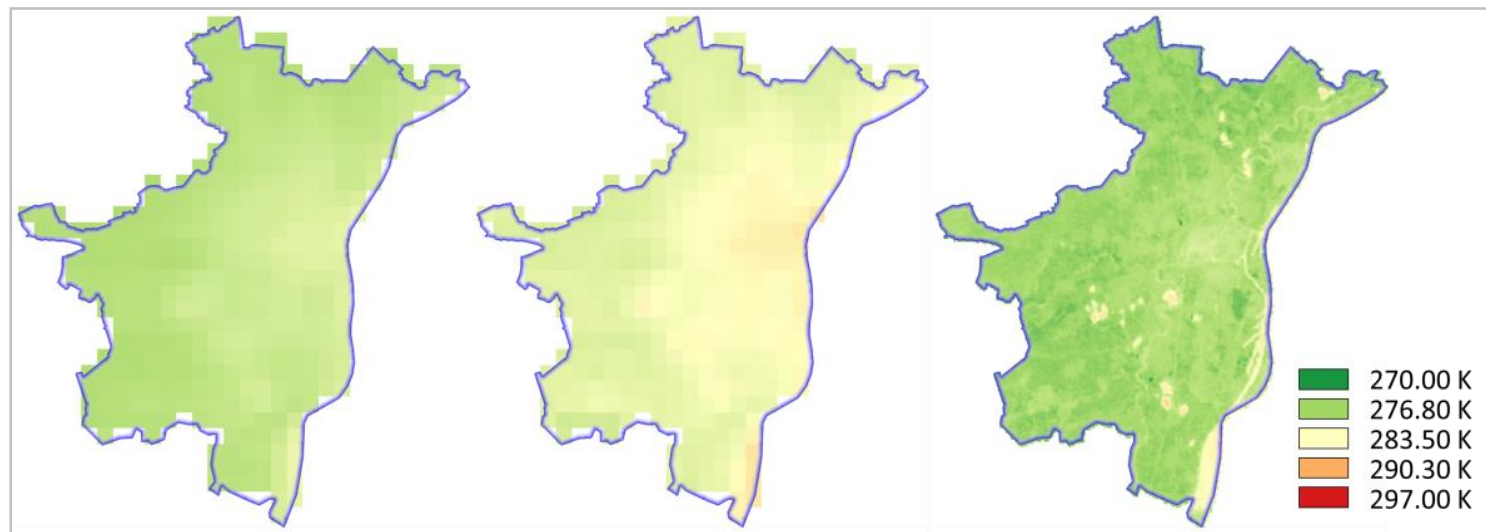

Figure 13. Autumn UHI map of Strasbourg at night when analysing all data from MODIS (left), typical days from MODIS

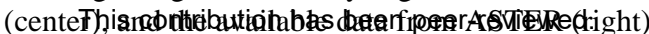


masses of water appear to be hot, even though it is a land cover with hardly any temperature variation between day and night.

\section{CONCLUSION AND OULOOK}

Thanks to the processing and analysis of LST Earth Observation (EO) data between 2012 and 2019 and its crossing with LCZ and land uses maps, it has been possible to: 1) validate the linear LST-AT model obtained in a previous study (Del Pozo et al., 2020) and give and explanation of its main atypical values, such as the one in La Wantzenau; 2) check that the linear model obtained improves when the LST-AT correlation is analysed by LCZ; 3) verify the importance that the spatial resolution of the satellite data has with respect to the LST-AT model results; 4) obtain the mean temperature values by season and LCZ as well as their variability; 5) reveal that natural surfaces such as dense trees, bush-scrub and water (LCZs A, D and G) act as temperature buffers and therefore are land surfaces that must be considered strategic to mitigate the UHI effect; and 6) obtain 3 UHI maps per season for the city of Strasbourg.

The results show complete information on the multitemporal thermal behavior of different urban environments, which are mainly associated with the urban structure and the properties of the surface cover. In general, the warmer areas were identified as the compact, medium or low-rise building types with little vegetation (LCZs 2,3,5), while the colder zones were recorded as vegetation zones (LCZs A,B,D). These findings provide information on climate-friendly urban planning towards sustainable urban development.

With respect to the EO data used, both LST from MODIS and from ASTER are validated to map the UHI effect with the disadvantage that ASTER, although offers higher spatial resolution, offers data on demand and, therefore, is limited to perform multitemporal LST analysis. However, thanks to its spatial resolution, better LST-AT results were obtained.

After this work, lines of research are opened to deepen on:

- $\quad$ Derived from the outliers found in the LST-AT model and by double checking the LCZ map and land use map, we have verified that there is some error in the LCZ map of Strasbourg used. It is proposed to optimize the LCZ map based on the discrepancies obtained in the LCZ-LST analyses, and regarding the scale of the LST data used. Weights can be introduced in the classification process in order to consider the size and the occurrence of neighbouring classes around the area under study.

- Investigate the cause of the high Standard deviation values of the mean LST variations per LCZ in winter from 2012 to 2019 using MODIS data when analyzing all cloudless images available (Table 3 ). Check if it may be due to the use of images with a blanket of snow over the city of Strasbourg.

- Perform the seasonal analysis through the average of the LST values of the 4 typical days per month that (Capderou, 1988) proposes instead of the typical day per season. Being that days: January 17, February 15, March 16, April 15, May 15, June 11, July 17, August 16, September 16, October 16, November 15 and December 11.

- Expand the study to a greater variety of EO products in order to: (1) strengthen the methodology and validate the results obtained and (2) check if there are still outliers for specific locations.
- Analyse daytime LST data from the Landsat-8 satellite with $100-\mathrm{m}$ of native resolution (30-m resolution if resampled) and 16 days of temporal resolution to perform both LST-AT analysis and evaluate daytime LST per LCZ and season.

\section{ACKNOWLEDGMENTS}

The authors would like to thank the Eurométropole Strasbourg for providing useful Opendata. Authors would also like to thank Iberdrola España SAU and Universidad de Salamanca by funding given for human resources through Cátedra Iberdrola VIII Centenario.

\section{REFERENCES}

Badaro-Saliba, N., Adjizian-Gerard, J., Zaarour, R., Najjar, G. (2021). LCZ scheme for assessing Urban Heat Island intensity in a complex urban area (Beirut, Lebanon). Urba Climate, 37, 100846.

Cai, M., Ren, C., Xu, Y., Lau, K. K. L., \& Wang, R. (2018). Investigating the relationship between local climate zone and land surface temperature using an improved WUDAPT methodology-A case study of Yangtze River Delta, China. Urban Climate, 24, 485-502.

Capderou, M. (1988). Atlas Solaire de l'Algérie. Alger : Office des publications universitaires.

Cho, D., Yoo, C., Im, J., Lee, Y., \& Lee, J. (2020). Improvement of spatial interpolation accuracy of daily maximum air temperature in urban areas using a stacking ensemble technique. GIScience \& Remote Sensing, 57(5), 633649 .

Del Pozo, S., Landes, T., Nerry, F., Kastendeuch, P., Najjar, G., Philipps, N., \& Lagüela, S. (2020). Uhi Estimation Based on Aster and Modis Satellite Imagery: First Results on Strasbourg City, France. ISPRS-International Archives of the Photogrammetry, Remote Sensing and Spatial Information Sciences, 43, 799-805

Kwok, Y. T., Schoetter, R., Lau, K. K. L., Hidalgo, J., Ren, C., Pigeon, G., \& Masson, V. (2019). How well does the local climate zone scheme discern the thermal environment of Toulouse (France)? An analysis using numerical simulation data. International Journal of Climatology, 39(14), 5292-5315.

Landes, T., Najjar, G., Koehl, M., Montauban, O., Gourguechon, C., Kastendeuch, P., Slisse, P. (2020). Création de cartes de zones climatiques locales pour le suivi des îlots de chaleur urbains à Strasbourg. Revue XYZ (AFT) n. 163, 53-61.

Ochola, E. M., Fakharizadehshirazi, E., Adimo, A. O., Mukundi, J. B., Wesonga, J. M., \& Sodoudi, S. (2020). Interlocal climate zone differentiation of land surface temperatures for Management of Urban Heat in Nairobi City, Kenya. Urban Climate, 31, 100540.

Quan, J. (2019). Multi-temporal effects of urban forms and functions on urban heat islands based on local climate zone classification. International journal of environmental research and public health, 16(12), 2140. 
Stewart, I. D., \& Oke, T. R. (2012). Local climate zones for urban temperature studies. Bulletin of the American Meteorological Society, 93(12), 1879-1900.

Wang, R., Cai, M., Ren, C., Bechtel, B., Xu, Y., \& Ng, E. (2019). Detecting multi-temporal land cover change and land surface temperature in Pearl River Delta by adopting local climate zone. Urban Climate, 28, 100455.

Zhou, X., Okaze, T., Ren, C., Cai, M., Ishida, Y., Watanabe, H., \& Mochida, A. (2020). Evaluation of urban heat islands using local climate zones and the influence of sea-land breeze. Sustainable Cities and Society, 55, 102060. 